\title{
Study of the effects of photoperiod and salinity in the Alvarado strain of the Brachionus plicatilis species complex (Rotifera: Monogononta)
}

\author{
Jesús David Moha-León ${ }^{1}$, Ignacio Alejandro Pérez-Legaspi ${ }^{1 *}$, \\ Martha Patricia Hernández-Vergara ${ }^{1}$, Carlos Iván Pérez-Rostro ${ }^{1}$ and Ricardo Clark-Tapia ${ }^{2}$ \\ 1 División de Estudios de Posgrado e Investigación, Instituto Tecnológico de Boca del Río, Km. 12 Carr. Veracruz-Córdoba, \\ Boca del Rio, Veracruz 94290, México \\ 2 Instituto de Estudios Ambientales, Universidad de la Sierra Juárez, Av. Universidad, Ixtlán de Juárez, Oaxaca 68725, México
}

Received 28 May 2015; Accepted 9 November 2015

\begin{abstract}
The survivorship and distribution of planktonic rotifers are influenced by salinity and photoperiod. In this study we performed life table experiments with the estuarine rotifer Brachionus sp., "Alvarado" strain (collected in Veracruz, Mexico). Three salinities: 7.5, 15 and 30\%o, and two photoperiods: constant light and $16: 8 \mathrm{~h}$ (light:dark) photoperiod at one temperature $\left(25 \pm 2{ }^{\circ} \mathrm{C}\right)$ were assessed. The microalgae Nannochloropsis oculata $\left(1 \times 10^{6}\right.$ cells. $\left.\mathrm{mL}^{-1}\right)$ was supplied as food. We recorded the hatching percentages at different temperatures, and we included morphometric data of adult rotifers, neonates and parthenogenetic eggs. Results showed that the highest estimated values of net reproductive potential (Ro), intrinsic growth rate $(r)$ and reproductive value $(\mathrm{Vx})$ were obtained at 15\% and 16:8 h (light:dark) photoperiod, followed by continuous light, respectively. The lowest reproductive rate was observed at $30 \% 0$ and $16: 8 \mathrm{~h}$ (light:dark) photoperiod. Hatching reached $100 \%$ after $20 \mathrm{~h}$ at temperatures of 25 and $30{ }^{\circ} \mathrm{C}$. The morphometric analysis of the lorica suggests that this $B$. "Alvarado" strain belongs to the SM clade of the B. plicatilis species complex. This strain of Brachionus is: (a) euryhaline, (b) high growth rate, (c) small size. All these characteristics suggest that this strain can be potentially used as live food for larval fish and for the development of toxicity tests.
\end{abstract}

Key words: Lifetable / growth potential / rotifer / clade / sympatry

\section{Introduction}

Rotifers are microscopic invertebrates present in estuarine, freshwater and marine environments (Pennak, 1989). There are three Classes currently recognized in the Phylum Rotifera: Seisonacea with three species, Bdelloidea with 461 species and Monogononta with 1570 species (Fontaneto et al., 2008; Segers, 2008). However, more species should be considered as a result of cryptic speciation (Segers, 2008), their size ranges between 50 and $2000 \mu \mathrm{m}$ in length (Wallace et al., 2006; Segers, 2008). Their small size and integument permeability make them susceptible to chemical and physical changes in their environments, establishing the limits of the habitat of species (Nogrady et al., 1993; Pérez-Legaspi and Rico-Martínez, 1998; Wallace et al., 2006). Brachionus plicatilis is a

*Corresponding author: ialegaspi@yahoo.com euryhaline rotifer which has been considered cosmopolitan due to its ample distribution (Yin and Zhao, 2008; Stelzer et al., 2011; Kostopulou et al., 2012). However, its taxonomic status nowadays is not clear, because several molecular studies suggest that it is a complex of cryptic species (Gómez, 2005; Stelzer et al., 2011; AlcántaraRodríguez et al., 2012; Kostopoulou et al., 2012), with different osmoregulatory capabilities (Lowe et al., 2005).

Salinity is an important factor that influences rotifer cultures (Lowe et al., 2005), where B. plicatilis is widely used in fish and crustacean marine larviculture (Kostopoulou et al., 2009, 2012; Conceição et al., 2010). The $B$. "Cayman" morphotype has been recognized as the most representative for aquaculture (Kostopoulou and Vadstein, 2007). Life tables offer useful information on the effect of environmental factors in the population structure of rotifers (Pérez-Legaspi et al., 2015), making it possible to estimate their population dynamics based on growth 
rates and mortality (Krebs, 1994; Wallace et al., 2006; Wallace and Snell, 2010). Population parameters like " $r$ " (intrinsic growth rate) depend on the type of clone of B. plicatilis, as well as on the interactions between temperature and salinity (Miracle and Serra, 1989). The highest growth rates have been recorded in salinities ranging from 5 to $20 \%$ for clones of B. plicatilis sensu stricto (Yin and Zhao, 2008); while in sister species the highest growth rates are recorded in salinities of $16-18 \%$ o (Lowe et al., 2007). On the other hand, Lubzens et al. (1985) suggest that salinity can be a modulator of growth rates in B. plicatilis influencing the genetic variation of the strain. Salinity causes local adaptation, genetic population divergence and speciation cryptic in the populations of the B. plicatilis species complex (Alcántara-Rodríguez et al., 2012). In addition, rotifers are very prone to local and regional differentiation because its ability to disperse; consequently the sympatry are very common in the B. plicatilis species complex, coexisting among them, being possible to find additional species in the sampled lineages (Gómez, 2005). Brachionus sp. "Alvarado" represents a new linage (and possibly a new species) of the B. plicatilis species complex which has not been completely genetically characterized. However, a preliminary analysis of the COI (citochrome c oxidase subunit I) sequence shows a strong relation with Brachionus ibericus and $B$. "Cayman", in a publication where the Alvarado strain was named Brachionus VER strain (Rico-Martínez et al., 2013); although the Alvarado strain also shows close relation to the $B$. "Almenara" strain (Jorge Ciros-Pérez, personal communication). Recently, García-Morales and Elías-Gutiérrez (2013) reported the presence of B. "Almenara" through the analysis of the COI sequence at the Sontecomapan Lagoon $(118.7 \mathrm{~km}$ away from Alvarado Lagoon), suggesting that this strain has great capability for dispersal and colonization. In the present study, we have decided to temporarily name our population as Brachionus sp. "Alvarado" strain base in the original collection site. Our strain shows a high reproductive rate and ease of culture. Therefore, it is important to assess its growth rate potential under different conditions of photoperiod and salinity, to determine its usefulness in aquaculture or for the development of further toxicity tests; in the meantime contributing to the knowledge of its reproductive biology, and comparing its characteristics with those of similar clades of the $B$. plicatilis species complex. The objective of this study was to assess the effect of the salinity and photoperiod in the life history of the rotifer Brachionus sp. "Alvarado" strain using: (a) life table experiments, (b) morphometric data and (c) hatching percentages.

\section{Materials and methods}

The rotifer Brachionus sp. "Alvarado" strain was collected in the Alvarado Lagoon, off the coast of southwest Veracruz, Mexico, in the Gulf of Mexico $\left(18^{\circ} 46^{\prime}-18^{\circ} 42^{\prime} \mathrm{N}\right.$ and $\left.95^{\circ} 34^{\prime}-95^{\circ} 58^{\prime} \mathrm{W}\right)$. The region has an annual temperature between 18 and $26^{\circ} \mathrm{C}$ and an average of $7.5 \%$ (2.2-14.3). This lagoon system receives freshwater from the rivers Papaloapan, Blanco, El Limón and Acula; besides, it is connected to the sea (De la Lanza-Espino and Lozano, 1999). Rotifer culture was implemented according to the protocol of Pérez-Legaspi and Rico-Martínez (1998) with slight modifications, and maintained for over 5 years in the following conditions: synthetic seawater at $15 \%$, using distilled water and aquarium salts (Oceanic, GAL aquarium, USA), with a $\mathrm{pH}$ of $8.2-8.4$, and a temperature of $25 \pm 2{ }^{\circ} \mathrm{C}$ and constant light at 3000 luxes. Additionally, the green algae Nannochloropsis oculata was acquired from the Centro de Investigación Científica y de Educación Superior de Ensenada (CICESE, Strain Number NNO1), used as food, and cultured in Guillard "F2" medium at 15\% (Stein, 1979).

To establish the temperature to be used during the experiments, we studied the hatching percentages at different temperatures $\left(20,25\right.$ and $\left.30 \pm 2{ }^{\circ} \mathrm{C}\right)$, in the following way: ten parthenogenetic eggs per well $(n=100)$ were placed in a new sterile transparent polystyrene plate (Costar, Corning Inc.), with $2 \mathrm{~mL}$ of synthetic seawater at $15 \%$. The plates were placed under constant light at 3000 luxes inside a bioclimatic chamber (Felisa), exposing the eggs to each temperature and recording the different times needed to achieve $100 \%$ hatching.

The life table experiments included a week of previous acclimation for each rotifer culture at 7.5, 15 and 30\%, respectively. The definitive experiments started using neonates $<2 \mathrm{~h}$ old. These neonates were obtained from parthenogenetic eggs and then placing one individual per well $(N=24)$ in a 24 -well polystyrene plate containing a total volume of $2 \mathrm{~mL}$ of synthetic seawater at each of the tested salinities $(7.5,15$ and $30 \%$ ), with an algal density of $1 \times 10^{6}$ cells.mL $\mathrm{m}^{-1}$ of $N$. oculata which was determined with a Neubauer chamber (Optik Labor, Germany). Consecutively, the plates were exposed to a temperature of $25 \pm 2{ }^{\circ} \mathrm{C}$, at 3000 luxes to assess: (a) continuous light, and (b) 16:8 h, light:dark photoperiod. Then, the adult organisms (parents) were observed every $12 \mathrm{~h}$, and the neonates (descendants) were counted and removed from the well. The medium was replaced with the same corresponding salinity and food concentration. Life tables were maintained until the last original parent died in each treatment.

Besides, according to Kostopoulou et al. (2009); we measured the lorica of parthenogenetic females (adult and neonates) and eggs cultured at the same salinities tested (7.5, 15 and $30 \%$ ), adding the $2.5 \%$ only for the morphometry. These measures were taken with a 10:100 reticulated micrometer (Carl Zeiss). We measure: total Lorica length (TL), maximum width (MW), the distance between the first and second external spine (DS1-2), and distance between spines (DS), and the external cover of the egg (E).

Data analysis included the estimation of the following population parameters: time interval of $12-\mathrm{h}(x)$, mean generation time $(\mathrm{Tc})$, net reproductive potential (Ro), intrinsic growth rate $(r)$, life expectancy (ex), reproductive value $(\mathrm{Vx})$, and finite index of increase $(\lambda)$; according to Krebs (1994), and Begon et al. (1996). These parameters 
Table 1. Life table of the rotifer Brachionus sp. "Alvarado" at different salinities and two types illumination regimes.

\begin{tabular}{llcccccc}
\hline Conditions & Salinity (\%) & $X$ & Ex & Tc & $r$ & Ro & $\lambda$ \\
\hline Photoperiod 16:8 h (light:dark) & 7.5 & 144 & 7.12 & 5.27 & 0.4817 & 12.69 & $1.6189 \pm 0.028$ \\
& 15 & 144 & 8.25 & 4.77 & 0.5336 & 18.09 & $1.7051 \pm 0.043$ \\
Continuous light & 30 & 180 & 7.60 & 7.82 & 0.3100 & 11.31 & $1.3630 \pm 0.026$ \\
& 7.5 & 144 & 7.41 & 5.27 & 0.5296 & 16.38 & $1.6980 \pm 0.043$ \\
& 15 & 216 & 9.18 & 6.72 & 0.4427 & 19.64 & $1.5570 \pm 0.048$ \\
& 30 & 216 & 9.18 & 6.91 & 0.4301 & 19.58 & $1.5375 \pm 0.051$ \\
\hline
\end{tabular}

$X$, hours; ex, life expectancy; Tc, mean generation time; $r$, intrinsic rate of natural increase; Ro, net reproductive rate; $\lambda$, infinite index of increase.

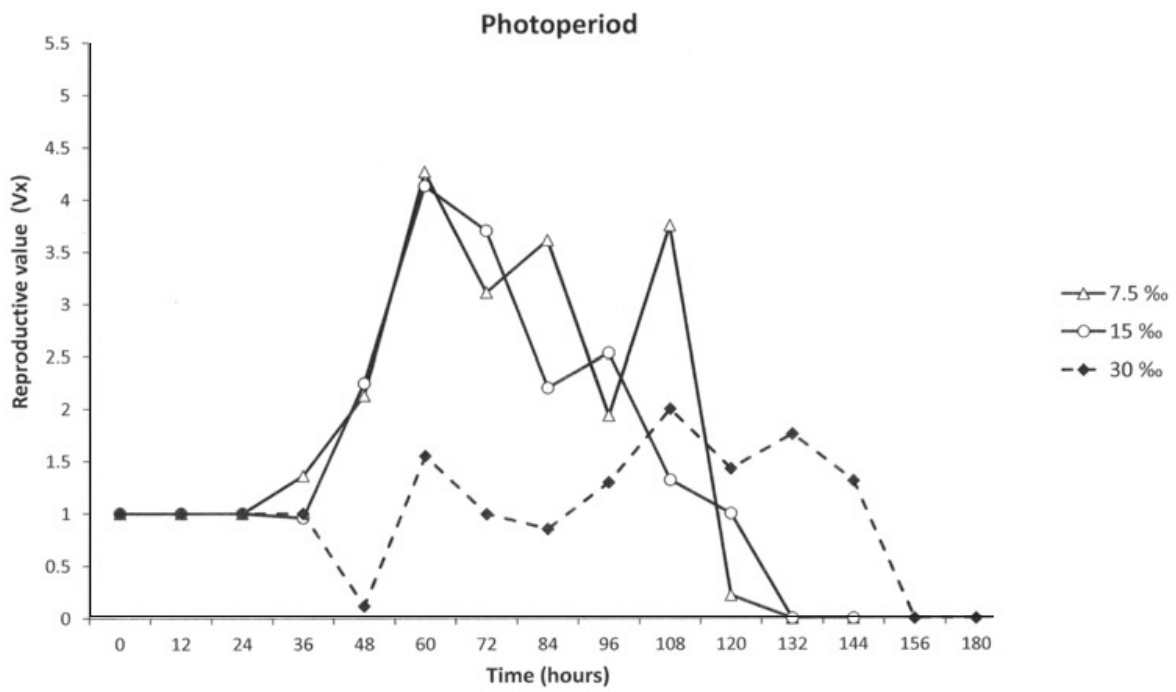

Fig. 1. Reproductive value ( $\mathrm{Vx})$ of Brachionus "Alvarado" cultured at different salinities at $25 \pm 2{ }^{\circ} \mathrm{C}$ under a $16: 8 \mathrm{~h}$ light:dark photoperiod.

were calculated using the software PopTools 2.7.5 (2006) for Microsoft Excel, with confidence intervals of $95 \%$, through 1000 Monte Carlo simulations (Alvarez-Buylla and Slatkin, 1993). We also performed single regression analysis between survivorship (lx) and life expectancy (ex) for each treatment. The morphometric data and the effects of photoperiod and salinities for all individuals in each treatment were analyzed by one way analysis of variance and post hoc comparisons by Tukey's tests $(P<0.05)$. The analysis was done using the software Statistica 7.0 (Statsoft, Inc., 2004).

\section{Results}

The best conditions to culture Brachionus sp. "Alvarado" were recorded when the population grows at $15 \%$, regardless of photoperiod (Table 1). However, it is possible to obtain high population densities in this strain when exposed to continuous light and salinities of 7.5 and $15 \%$, as shown in our analysis of Vx (Figs. 1 and 2). Under continuous light rotifers produce neonates after $36 \mathrm{~h}$ for the three tested salinities, and the highest Vx was attained at $7.5 \%$, but with a moderate longevity (Fig. 1). The highest values of Ro were recorded at 15 and $30 \%$ when rotifers are exposed to continuous light. The lowest Ro value was obtained at 7.5\% under continuous light, but this value is higher than any of the Ro values obtained at $(16: 8,1: d)$ photoperiod. The highest Ro values with photoperiod were obtained at $15 \%$. Similarly, the $r$ values were higher under continuous light that is, under photoperiod at salinities of 7.5 and $30 \%$. However, the highest $r$ value was attained at 15\% under photoperiod (Table 1). The statistical analysis shows that there is no significant effect among the continuous light and the salinities tested; while the photoperiod and salinities are significant $(P<0.05)$ (Table 2$)$. In general, rotifers grow better at $15 \%$ in photoperiod and continuous light, respectively; followed by 30\% under continuous light (Table 1). On the other hand, the correlation coefficient (adjusted $R^{2}$ ) between survivorship (lx) and life expectancy (ex), shows that there is good correlation for all treatments (Table 3).

The hatching percentage of parthenogenetic eggs was $100 \%$ at $20 \mathrm{~h}$ at 25 and $30{ }^{\circ} \mathrm{C}$, while only $80 \%$ was recorded at $20{ }^{\circ} \mathrm{C}$, respectively (Fig. 3). The morphometric data of the lorica of parthenogenetic females (adults and neonates) and eggs of Brachionus "Alvarado" is shown in Table 4 . We found significant differences $(P<0.05)$ in TL and $\mathrm{MW}$ between adults and neonates, and adults grew larger at 30\% (Fig. 4). Our morphometric data support the inclusion of Brachionus "Alvarado" (Fig. 5) in the SM clade of $B$. plicatilis species complex. Neither sexual females nor males were measured, because they have never 


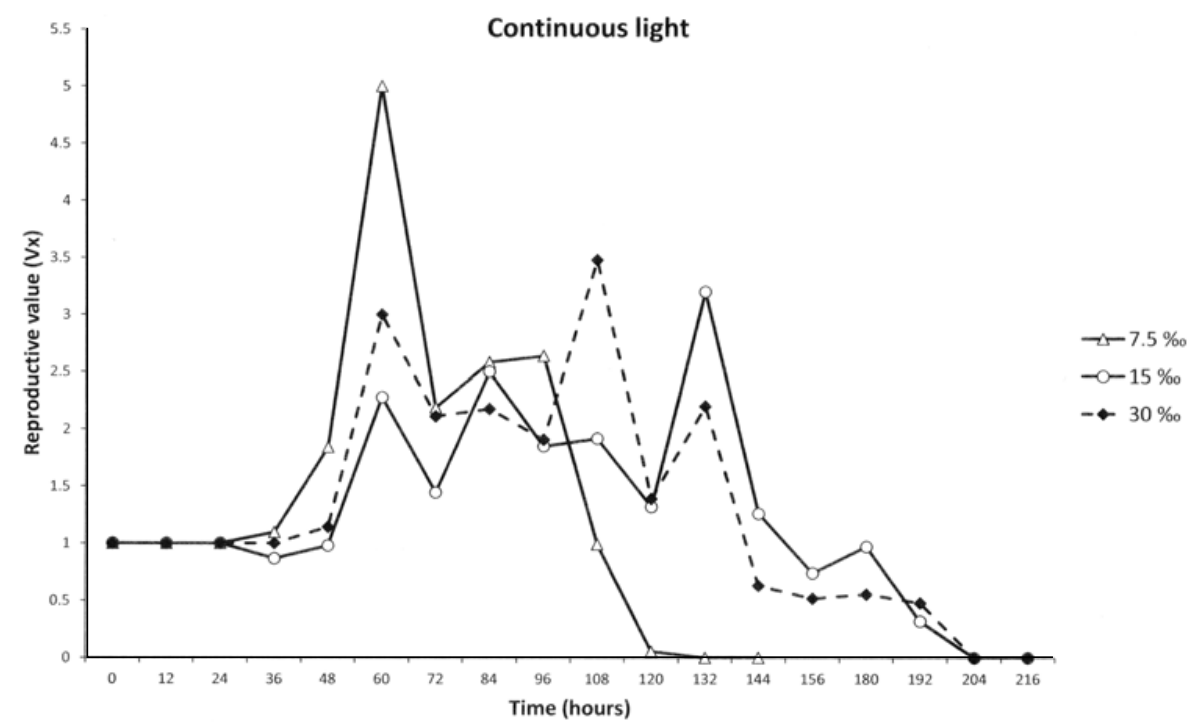

Fig. 2. Reproductive value (Vx) of Brachionus "Alvarado" cultured at different salinities at $25 \pm 2{ }^{\circ} \mathrm{C}$ under continuous light.

Table 2. Analysis of variance (one-way ANOVA) performed for continuous light, photoperiod and the morphometry for the rotifer of Brachionus sp. "Alvarado" exposed to several salinities.

\begin{tabular}{|c|c|c|c|c|c|}
\hline Effect & SS & d.f. & MS & $F$ & $P$ \\
\hline \multicolumn{6}{|c|}{ Continuous light } \\
\hline Intercept & 52710.14 & 1 & 52710.14 & 100.5386 & 0.000000 \\
\hline Salinity & 313.18 & 2 & 156.59 & 0.2987 & $0.743225^{\mathrm{ns}}$ \\
\hline Error & 24116.78 & 46 & 524.28 & & \\
\hline \multicolumn{6}{|c|}{ Photoperiod } \\
\hline Intercept & 32606.59 & 1 & 32606.59 & 65.74141 & 0.000000 \\
\hline Salinity & 8403.64 & 2 & 4201.82 & 8.47171 & $0.000907^{*}$ \\
\hline Error & 18847.33 & 38 & 495.98 & & \\
\hline \multicolumn{6}{|c|}{ Adult (TL) } \\
\hline Intercept & 2852390 & 1 & 2852390 & 18840.42 & 0.000000 \\
\hline Salinity & 8249 & 3 & 2750 & 18.16 & $0.000000^{*}$ \\
\hline Error & 11506 & 76 & 151 & & \\
\hline \multicolumn{6}{|c|}{ Neonate (TL) } \\
\hline Intercept & 1701486 & 1 & 1701486 & 14255.57 & 0.000000 \\
\hline Salinity & 1482 & 3 & 494 & 4.14 & $0.008995^{*}$ \\
\hline Error & 9071 & 76 & 119 & & \\
\hline \multicolumn{6}{|c|}{ Adult (MW) } \\
\hline Intercept & 1808410 & 1 & 1808410 & 15025.11 & 0.000000 \\
\hline Salinity & 737 & 3 & 246 & 2.04 & $0.115233^{\mathrm{ns}}$ \\
\hline Error & 9147 & 76 & 120 & & \\
\hline \multicolumn{6}{|c|}{ Neonate (MW) } \\
\hline Intercept & 909084.8 & 1 & 909084.8 & 5636.677 & 0.000000 \\
\hline Salinity & 3981.9 & 3 & 1327.3 & 8.230 & $0.000082 *$ \\
\hline Error & 12257.3 & 76 & 161.3 & & \\
\hline
\end{tabular}

TL, total length of the lorica; MW, maximum width of the lorica; SS, sum of squares; d.f., degree of freedom; MS, mean squares; $F, F-$ ratio; $P, P$ value. *Significant $(P<0.05)$, ns, non-significant $P>0.05 ; N=24$.

been observed for this strain since the initial culture was established 5 years ago.

\section{Discussion}

The Ro, $r$ and $\mathrm{Vx}$ values indicate that the best culture conditions for Brachionus sp. "Alvarado" are achieved at $15 \%$ salinity and under photoperiod or continuous light
(Figs. 1 and 2, Table 1), which falls under the range reported by Yin and Zhao (2008) for B. plicatilis s.s. However, it is also possible to obtain high densities of rotifers under continuous light at salinities of 7.5 and $30 \%$. It appears that continuous light positively influences reproduction of Brachionus "Alvarado", increasing life expectancy (ex) and generation time (Tc) where the highest values were recorded (Table 1). However, there is no significant difference among the treatments in continuous 
light, but still it is possible to distinguish that $15 \%$ favors reproduction in this rotifer strain regardless of illumination type or photoperiod (Fig. 3); although the photoperiod has a significant effect on the salinities tested $(P<0.05)$ (Table 2$)$.

In our strain only parthenogenetic females are present, thus the life tables were performed with parthenogenetic females; they are consider as the step of life history exposed most of the time to natural selection (Stelzer, 2005). In a recent toxicological study where our strain was used,

Table 3. Coefficient of determination $\left(R^{2}\right)$ between survivorship (lx) and the mean life expectancy (ex) for all treatments assessed with the rotifer Brachionus sp. "Alvarado".

\begin{tabular}{lccc}
\hline Condition/Salinity & $7.5 \% 0$ & $15 \% 0$ & $30 \% 0$ \\
\hline Photoperiod & 0.7962 & 0.8240 & 0.7723 \\
Continuous light & 0.8096 & 0.7120 & 0.7120 \\
\hline
\end{tabular}

sexual females and males were never encountered in spite of the culture was maintained for 10 months (RicoMartínez et al., 2013). These authors suggest that perhaps this strain is unable to produce cysts under laboratory conditions. Some authors argued that salinity is one of the most important factors that influence cyst production in B. plicatlis (Hagiwara et al., 1989). The lack of cyst production under laboratory conditions could be considered as an advantage for the use of $B$. "Alvarado" in aquaculture, because parthenogenesis eliminates the cost of producing males which allows for rapid parthenogenetic population growth (Kostopoulou et al., 2012). However, further studies are needed to determine if sexuality can be induced in this strain with the appropriate stimulus.

Salinity may influence evolutionary and ecological processes of rotifers (Alcántara-Rodríguez et al., 2012). The range of salinity tolerance shown by our strain is characteristic of the $B$. plicatilis species complex, with

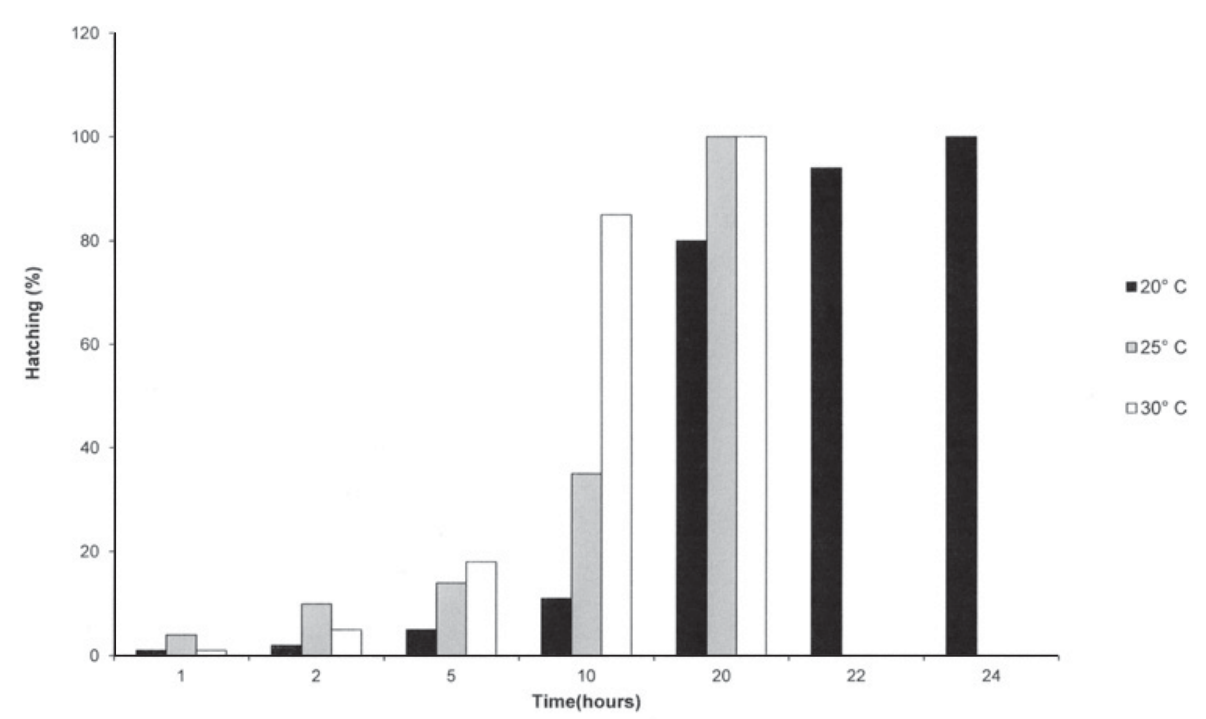

Fig. 3. Hatching percentage of the rotifer Brachionus sp. "Alvarado" exposed to different temperatures at $15 \%$ salinity.

Table 4. Morphological characterization of the rotifer Brachionus sp. "Alvarado". Organisms were taken randomly from different cultures maintained at several salinities at $25 \pm 2{ }^{\circ} \mathrm{C}$; we measured adult females (A), neonates (N) $(<30$ min old) and parthenogentic eggs (E). The values are in micrometers and correspond to the mean \pm one standard deviation $(N=20)$.

\begin{tabular}{|c|c|c|c|c|c|}
\hline \multirow[b]{2}{*}{ Salinity $(\% 0)$} & \multirow[b]{2}{*}{ Stage } & \multicolumn{2}{|c|}{ Lorica } & \multicolumn{2}{|c|}{ Spines } \\
\hline & & TL & MW & DS1-2 & $\mathrm{DS}$ \\
\hline \multirow[t]{3}{*}{2.5} & $\mathrm{~A}$ & $177.5 \pm 15.34$ & $153.9 \pm 15.87$ & $21.45 \pm 25.6$ & $89 \pm 6.40$ \\
\hline & $\mathrm{N}$ & $151.2 \pm 7.23$ & $114.25 \pm 8.15$ & $11.85 \pm 2.97$ & $67.75 \pm 11.9$ \\
\hline & $\mathrm{E}$ & $107.5 \pm 11.06$ & $90.2 \pm 6.34$ & & \\
\hline \multirow[t]{3}{*}{7.5} & A & $182.5 \pm 8.66$ & $149.75 \pm 8.34$ & $22.1 \pm 2.46$ & $91.5 \pm 8.12$ \\
\hline & $\mathrm{N}$ & $144.85 \pm 8.45$ & $122.65 \pm 16.3$ & $12.6 \pm 42.0$ & $69.05 \pm 9.33$ \\
\hline & $\mathrm{E}$ & $119.75 \pm 6.38$ & $87.95 \pm 4.68$ & & \\
\hline \multirow[t]{3}{*}{15} & A & $191 \pm 9.67$ & $152 \pm 8.94$ & $22.2 \pm 3.99$ & $94.5 \pm 12.34$ \\
\hline & $\mathrm{N}$ & $139.5 \pm 15.03$ & $97.5 \pm 12.92$ & $11.4 \pm 2.34$ & $64.5 \pm 9.98$ \\
\hline & $\mathrm{E}$ & $116.25 \pm 11.5$ & $78 \pm 7.67$ & & \\
\hline \multirow[t]{3}{*}{30} & A & $204.3 \pm 14.19$ & $145.75 \pm 8.92$ & $22.35 \pm 2.68$ & $91 \pm 7.18$ \\
\hline & $\mathrm{N}$ & $147.7 \pm 11.29$ & $102 \pm 12.07$ & $13.2 \pm 2.19$ & $66.75 \pm 6.54$ \\
\hline & $\mathrm{E}$ & $113.5 \pm 10.01$ & $81.55 \pm 9.9$ & & \\
\hline
\end{tabular}

TL, total length; MW, maximum width; DS1-2, distance between first spine and second external spine; DS, distance between spines; $\mathrm{E}$, external cover of egg. 


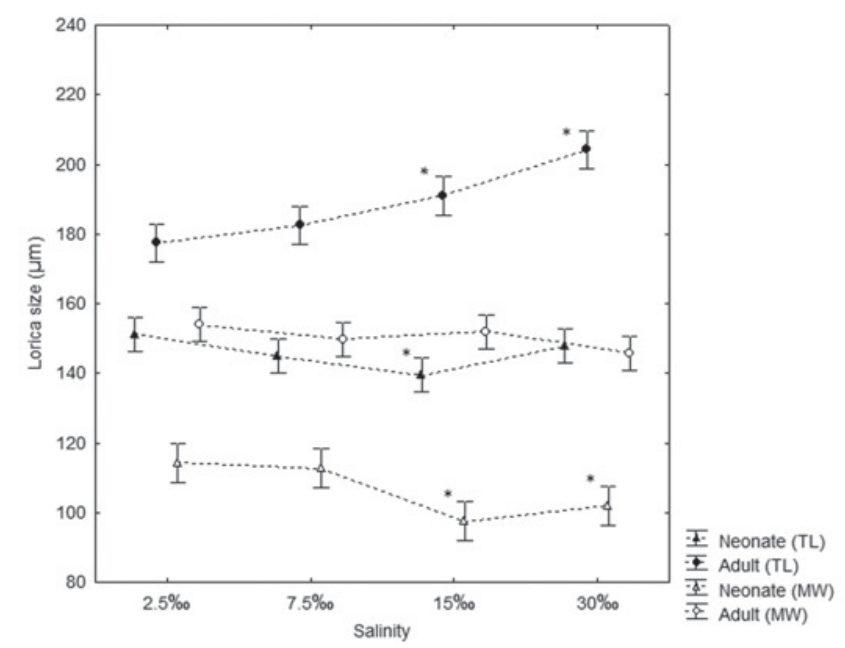

Fig. 4. Morphometric analysis of the lorica of Brachionus sp. "Alvarado" at different salinities. *Significant $(P<0.05)$.

rapid maximum growth occurring at moderate salinities at 10-20\%o, increasing at high salinities for marine species, which means that the $B$. plicatilis species complex shows close relation with its habitat depending on the genotype (Miracle and Serra, 1989; Anitha and George, 2006); showing a higher " $r$ " as a result of adaptation to an optimum salinity (Anitha and George, 2006). B. "Alvarado" shows a decrease in the growth rate when salinity increases at $30 \%$, perhaps because this strain is originated in a coastal lagoon with moderate salinity. The experiments performed in this study demonstrate that reproductive value decreases at $30 \%$ in comparison with other salinities under the same illumination conditions. This can be explained by a high consumption of ATP due to the intense activity of the ATPase $\mathrm{Na}^{+} / \mathrm{K}^{+}$at high salinities, which drives a decrease in growth and reproduction (Lowe et al., 2005).

The $R^{2}$ values show a strong relationship between survivorship and life expectancy in all treatments (Table 3 ). On the other hand, the $100 \%$ hatching of parthenogenetic eggs were completed at $20 \mathrm{~h}$ at 30 and $25^{\circ} \mathrm{C}$, while at $20{ }^{\circ} \mathrm{C}$, at $20 \mathrm{~h}$ only $85 \%$ was recorded. The $100 \%$ hatching rate was achieved at $24 \mathrm{~h}$. These experiments are allowed to consider $25^{\circ} \mathrm{C}$ as an adequate temperature for all treatments and to obtain a better hatching percentage for this rotifer strain (Fig. 3). Fielder et al. (2000), mention that salinity has higher effect than temperature. However, it is convenient to develop further studies to assess the effect of temperature in the life history of Brachionus "Alvarado".

Kostopoulou et al. (2009) suggest that the length of the lorica seems to be the most conserved character in spite of environmental variations. However it should be included in the genetic analysis to discriminate the lineages. Nevertheless, morphometry is useful to study the size range of species/lineages in the $B$. plicatilis species complex to detect phenotypical variation. The size and morphology of the lorica are not good indicators of the species boundaries (Suatoni et al., 2006). The morphometric analysis of the lorica of Brachionus sp. "Alvarado"
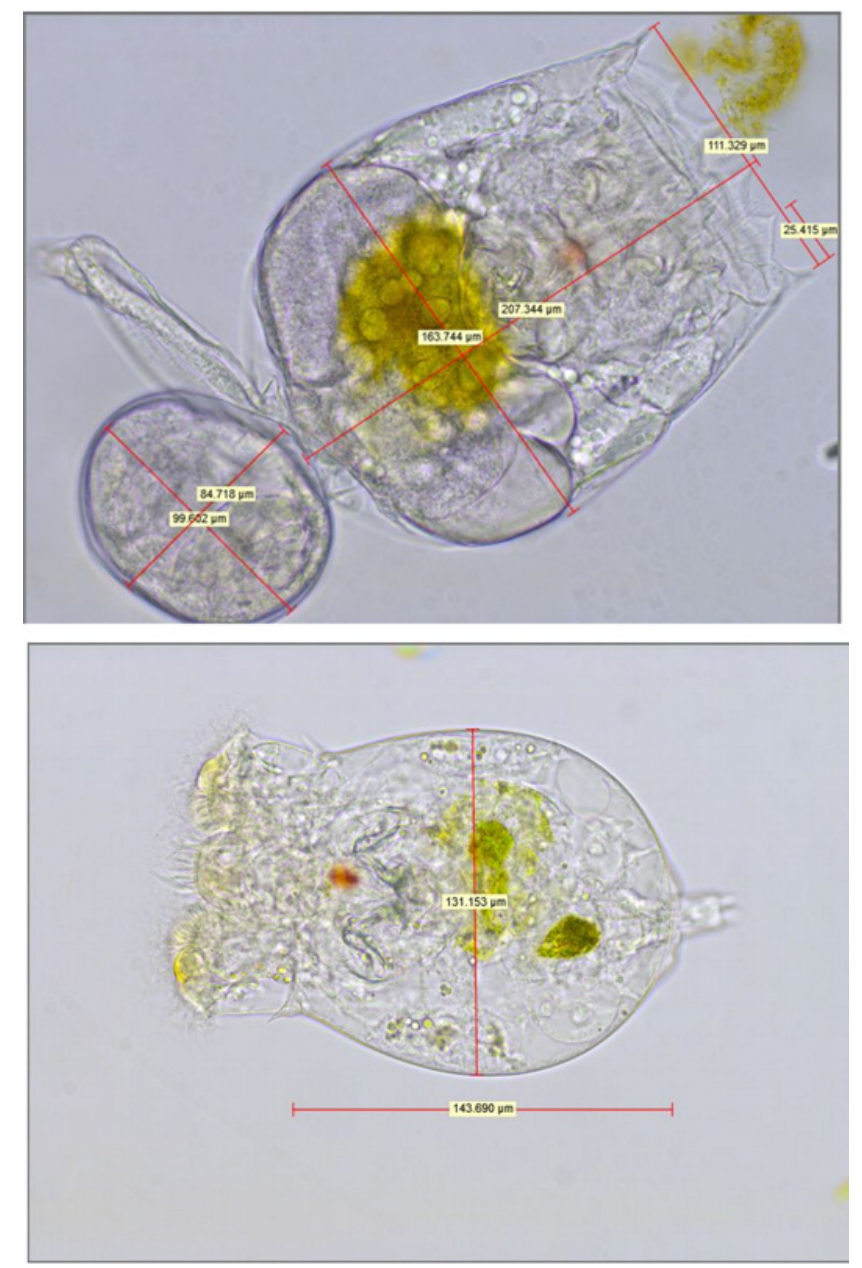

Fig. 5. Parthenogenetic female of Brachionus sp. "Alvarado" at $15 \%$ o $(40 \times)$. Adult with one parthenogenetic egg (upper) and neonate $<24$ h old (lower).

shows that this strain acts as an osmoconformer organism (Table 4) (Lowe et al., 2005), showing a more slender and elongated lorica when the salinity is increased. Anitha and George (2006) suggest that salinity influences in the osmoregulatory ability in rotifers which is in turn dependent of the genotype. Furthermore, the dimensions of $B$. "Alvarado" (177.5-204.3 $\mu \mathrm{m})$ include this strain in the Medium Morphotype such as SM-clade (150-220 $\mu \mathrm{m})$, in agreement with Conceição et al. (2010) and RicoMartínez et al. (2013), and related to the dimensions reported for B. ibericus $(193.5 \mu \mathrm{m})$ and B. "Almenara" (164-231 um) (Kostopoulou et al., 2009). Previous genetic analysis through an incomplete COI sequence and morphometric analysis suggest that our strain is closely related to $B$. Almenara (Jorge Ciros-Pérez, personal communication), and the strain $B$. Cayman and B. ibericus (Rico-Martínez et al., 2013); B. Almenara was recorded for the Sontecomapan Lagoon (GarcíaMorales and Elías-Gutiérrez, 2013) near of Alvarado Lagoon, both are connected to the Gulf of Mexico. This does not rule out the possibility that several strains coexist in the same aquatic system (Jorge Ciros-Pérez, personal 
communication). Perhaps, one rotifer strain with higher growth rate such as $B$. Cayman would be the most representative (Kostopoulou and Vadstein, 2007). It is possible to find many species of the complex $B$. plicatilis that sometimes coexist in sympatry, subject to the seasonal successions, temporary partition of the niche, predation or parasitism (Gómez, 2005). Depending on the environmental variations such as salinity affects the differentiation of niches for each strain, as in the case of B. plicatilis and Brachinus manjavacas; which can coexist with different growth rates as adaptive differential response to salinity (Montero-Pau et al., 2011). These ecological differences can occur when the clones belong to different lineages with optimal growth rates and patterns of mixis (Gómez, 2005). It is necessary to develop further studies that evaluate the limits of gene flow between sympatric species of the B. plicatilis complex, using specific mate recognition systems (Gómez et al., 1997), as well as molecular methods (Gómez et al., 1997; Gómez, 2005). This data provide preliminary information that contributes to the characterization of this new strain, although it is necessary to perform a thorough genetic analysis. The information generated in this study is useful to improve the intensive culture of the rotifer Brachionus "Alvarado" in the same way as those other strains such as $B$. Cayman are used in aquaculture, then B. "Alvarado" can be potentially used as live fed considering the fast growth, easy to culture, size and salinity tolerance; or to supply enough organisms to develop toxicity tests with a strain that is part of the $B$. plicatilis species complex from tropical aquatic ecosystems.

\section{Conclusions}

The best culture conditions for the rotifer B. "Alvarado" occurred at $15 \%$ salinity regardless of the illumination provided. This strain did not produce cysts in the laboratory conditions tested; this can be an advantage for aquaculture use because it allows producing parthenogenetic populations with rapid growth. The $100 \%$ hatching rate was achieved at $20 \mathrm{~h}$ at 25 and $30^{\circ} \mathrm{C}$. The morphometric data of Brachionus "Alvarado" showed that it is part of the SM clade in the B. plicatilis species complex. This study shows the feasibility of the use of this strain for aquaculture as live fed or to develop toxicity tests.

Acknowledgements. This project was carried out with the support provided by Dirección General de Educación Superior Tecnológica (DGEST, PROIFOPEP 2012: 4511.12-P). The authors are grateful for the valuable comments of Jorge CirosPérez. Also, thanks to anonymous reviewers by their valuable observations and recommendations to improve this manuscript.

\section{References}

Alcántara-Rodríguez J.A., Ciros-Pérez J., Ortega-Mayagoitia E., Serrania-Soto C.R. and Piedra-Ibarra E., 2012. Local adaptation in populations of a Brachionus group plicatilis cryptic species inhabiting three deep crater lakes in Central Mexico. Freshwater Biol., 57, 728-740.

Alvarez-Buylla E. and Slatkin M., 1993. Finding confidence intervals limits on population growth rates: Monte Carlo test of a simple analytic method. Oikos, 68, 273-283.

Anitha P.S. and George R.M., 2006. The taxonomy of Brachionus plicatilis species complex (Rotifera: Monogononta) from the Southern Kerala (India) with a note on their reproductive preferences. J. Mar. Biol. Ass. India, 48, 6-13.

Begon M., Harper J.L. and Townsend C.P., 1996. Ecology: Individuals, Populations, and Communities (3rd edn), Blackwell Scientific Publications, Oxford, 1068 p.

Conceição L.E.C., Yúfera M., Makridis P., Morais S. and Dinis M.T., 2010. Live feeds for early stages of fish rearing. Aquac. Res., 41, 613-640.

De la Lanza-Espino G. and Lozano H., 1999. Comparación fisicoquímica de las lagunas de Alvarado y Términos. Hidrobiológica, 9, 15-30.

Fielder D.S., Purser G.J. and Battaglene S.C., 2000. Effect of rapid changes in temperature and salinity on availability of the rotifers Brachionus rotundiformis and Brachionus plicatilis. Aquaculture, 189, 85-99.

Fontaneto D., De Smet H.D. and Melone G., 2008. Identification key to the genera of marine rotifers worldwide. Meiofauna Mar., 16, 75-99.

García-Morales A.E. and Elías-Gutiérrez M., 2013. DNA barcoding of freshwater rotifera in Mexico: evidence of cryptic speciation in common rotifers. Mol. Ecol. Resour., 13, 1097-1107.

Gómez A., 2005. Molecular ecology of rotifers: from population differentiation to speciation. Hydrobiologia, 546, $1-17$.

Gómez A., Carmona M.J. and Serra M., 1997. Ecological factors affecting gene flow in the Brachionus plicatilis complex (Rotifera). Oecologia, 111, 350-356.

Hagiwara A., Lee C.-S., Miyamoto G. and Hino A., 1989. Resting egg formation and hatching of the S-type rotifer Brachionus plicatilis at varying salinities. Mar. Biol., 103, 327-332.

Kostopoulou V. and Vadstein O., 2007. Growth performance of the rotifers Brachionus plicatilis, $B$. 'Nevada' and $B$. 'Cayman' under different food concentrations. Aquaculture, 273, 449-458.

Kostopoulou V., Miliou H. and Verriopoulos G., 2009. Morphometric changes in a strain of the lineage 'Nevada', belonging to the Brachionus plicatilis (Rotifera) complex. Aquac. Res., 40, 938-949.

Kostopoulou V., Carmona M.J. and Divanach P., 2012. The rotifer Brachionus plicatilis: an emerging biotool for numerous applications. J. Biol. Res-Thessalon, 17, 97-112.

Krebs C.J., 1994. Ecology, the Experimental Analysis of Distribution and Abundance (4th edn), Harper-Collins, New York, 801 p.

Lowe C.D., Kemp S.J., Bates A.D. and Montagnes D.J.S., 2005. Evidence that the rotifer Brachionus plicatilis is not an osmoconformer. Mar. Biol., 146, 923-929.

Lowe C.D., Kemp S.J., Díaz-Avalos C. and Montagnes D.J.S., 2007. How does salinity tolerance influence the distributions of Brachionus plicatilis sibling species? Mar. Biol., 150, 377-386. 
Lubzens E., Minkoff G. and Marom S., 1985. Salinity dependence of sexual and asexual reproduction in the rotifer Brachionus plicatilis. Mar. Biol., 85, 123-126.

Miracle M.R. and Serra M., 1989. Salinity and temperature influences in rotifer life history characteristics. Hydrobiologia, 186/187, 81-102.

Montero-Pau J., Ramos-Rodríguez E., Serra M. and Gómez A., 2011. Long-term coexistence of rotifer cryptic species. PLoS ONE, 6, e21530.

Nogrady T., Wallace R.L. and Snell T.W., 1993. Guides to the Identification of the Microinvertebrates of the Continental Waters of the World: Volume 4: Rotifera, SPB Academic Publishing, Leiden, The Netherlands, 142 p.

Pennak R.W., 1989. Freshwater Invertebrates of the United States (3rd edn), Wiley, New York, USA, 628 p.

Pérez-Legaspi I.A. and Rico-Martínez R., 1998. Effect of temperature and food concentration in two species of littoral rotifers. Hydrobiologia, 387/388, 341-348.

Pérez-Legaspi I.A., García-Villar A.M., Garatachia-Vargas M., Hernández-Vergara M.P., Pérez-Rostro C.I. and OrtegaClemente L.A., 2015. Influencia de la temperatura y tipo de alimento en la historia de vida de Ceriodaphnia cornuta SARS 1885 (Crustacea: Cladocera). Revista Investigación y Ciencia de la Universidad Autónoma de Aguascalientes, 64, 11-18.

Rico-Martínez R., Snell T.W. and Shearer T.L., 2013. Synergistic toxicity of Macondo crude oil and dispersant Corexit 9500A® to the Brachionus plicatilis species complex (Rotifera). Environ. Pollut., 173, 5-10.
Segers H., 2008. Global diversity of rotifers (Rotifera) in freshwater. Hydrobiologia, 595, 49-59.

Statsoft, Inc. 2004. STATISTICA (data analysis software system), version 7. www.statsoft.com.

Stein J., 1979. Handbook of Phycological Methods, Culture Methods and Growth Measurement, Cambridge University Press, Cambridge, 448 p.

Stelzer C.P. 2005. Evolution of rotifer life histories. Hydrobiologia, 546, 335-346.

Stelzer C.P., Riss S. and Stadler P., 2011. Genome size evolution at the speciation level: the cryptic species complex Brachionus plicatilis (Rotifera). Evol. Biol., 11, 90.

Suatoni E., Vicario S., Rice S., Snell T. and Caccone A., 2006. An analysis of species boundaries and biogeographic patterns in a cryptic species complex: the rotifer - Brachionus plicatilis. Mol. Phylogenet. Evol., 41, 86-98.

Wallace R.L. and Snell T.W., 2010. Rotifera. In: Thorp J.H. and Covich A.P. (eds.), Ecology and Classification of North American Freshwater Invertebrates, Academic Press, New York, 173-235.

Wallace R.L., Snell T.W., Ricci C. and Nogrady T., 2006. Rotifera. Volume 1: Biology, ecology and systematics. In: Segers H. and Dumont H.J. (eds.), Guides to the Identification of the Microinvertebrates of the World, No. 23 (2nd edn), Backhuys Publishers, Leiden, The Netherlands, 299 p.

Yin X.W. and Zhao, W., 2008. Studies on life history characteristics of Brachionus plicatilis O. F. Müller (Rotifera) in relation to temperature, salinity and food algae. Aquat. Ecol., 42, 165-176. 